
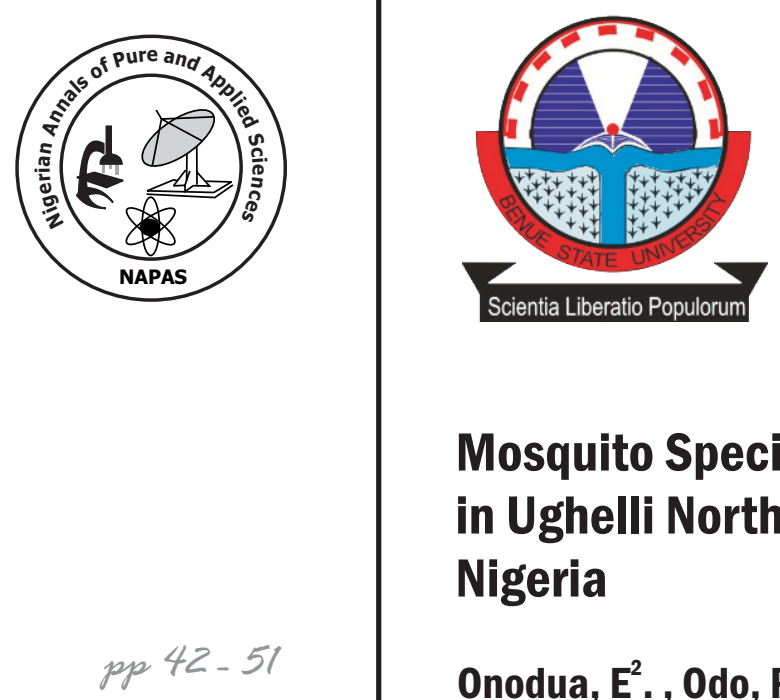

\title{
Mosquito Species Abundance, Distribution and Diversity in Ughelli North Local Government Area, Delta State, Nigeria
}

\author{
Onodua, $E^{2}$. , Odo, P.E ${ }^{* 1}$ and Egwunyenga, A. ${ }^{2}$. \\ ${ }^{1}$ Department of Animal and Environmental Biology, \\ Faculty of Life Sciences, University of Benin, Benin City, Edo State, Nigeria \\ ${ }^{1}$ Department of Animal and Environmental Biology, \\ Faculty of Science, Delta State University, Abraka, Delta State, Nigeria \\ Corresponding Author: odopatrickemeka@gmail.com, \\ Patrick.odo@lifesci.uniben.edu.
}

\begin{abstract}
This research was carried out to record mosquito species abundance, distribution, diversity and breeding sites in four villages of Ughelli North Local Government Area of Delta State. Potential habitats of mosquitoes were sampled using dippers, hand-lens and plastic containers between June and November 2014. A total number of 274 sites were examined and only 146 were positive for mosquito larvae. The habitats sampled include domestic containers $107(39.05 \%)$, puddles $59(21.53 \%)$, tyres $47(17.15 \%)$ and drains $61(22.26 \%)$. The variation in the number of larvae collected from the various habitats were not significant $(\mathrm{P}=0.1203, \mathrm{~F}=2.705$ and $\mathrm{df}=3$ ). One thousand six hundred and fifty-three (1.653) mosquito larvae were collected and reared to adults. Seven hundred and twelve (712) of the larvae emerged as adults that were separated into three genera: Anopheles, Aedes and culex and identified up to species level. Culex quinquefasciatus was found to be the most abundant (29.35\%) in the study area, followed by Aedes aegypti (25.70\%). C. nebulosus was the least abundant species with $2.95 \%$. Domestic containers were the most preferred breeding habitats for all the mosquito species and the variation in the species of mosquito with respect to types of habitat showed significant association in Ofuoma $(\mathrm{P}=0.0167, \mathrm{~F}=4.322, \mathrm{df}=3)$ and Adjekota $(\mathrm{P}=0.0252, \mathrm{~F}=3.852, \mathrm{df}=3)$. There was significant difference in the occurrence of mosquito species in the month of September (p value 0.0085) compared to June ( $\mathrm{p}$ value 0.0518 ), July ( $\mathrm{p}$ value 0.2370 ), August ( $\mathrm{p}$ value 0.1920 ), October ( $\mathrm{p}$ value 0.0534 ) and November ( $\mathrm{p}$ value 0.0241 . Variations existed in the physico-chemical parameters in the different sources of collections in different locations. Temperature ranged from 20.0 to $24.6^{\circ} \mathrm{C}$ while $\mathrm{pH}$ (hydrogen ion concentration) range was $6.9-7.7$ and Dissolved oxygen (D.O) ranged between 1.4 and $2.7(\mathrm{mg} / \mathrm{L}$ ) as Conductivity ranged between 67.9 and $82.1(\mu \mathrm{s})$ and turbidity varied from $62.0 \mathrm{NTU}$ in the container samples to $84.2 \mathrm{NTU}$ in the gutter samples and depth varied between 6.3 and $68.3(\mathrm{~cm})$ across the different locations but depth ranged from $6.3 \mathrm{~cm}$ to $68.3 \mathrm{~cm}$ and temperature was $(22.8 \pm 2.6)$, Analysis of variance (ANOVA) and mean was used to determine the significant differences $(p<0.05)$ in habitats and species distribution while Shannon Wiener and Simpson indices were used to determine species diversity and abundance. There is need for concerted efforts in mosquito control in Ughelli North to mitigate the incidence of mosquito transmitted diseases.
\end{abstract}

Key words: Culex quinquefasciatus, Aedes aegypti, C. nebulosus, Anopheles, Aedes and Culex 


\section{Introduction}

Mosquitoes are widely distributed throughout the world and they utilize different water bodies for their breeding (WHO 1982). Many species breed in both natural and artificial habitats which include pools, gutters, coconut shells, tree holes, bamboo, strips leaves axis and septic tanks (Aigbodion and Anyigwe 2005). The distribution of mosquitoes is influenced directly or indirectly by climatic and environmental factors (Mafiana et al., 1998). Mosquitoes prefer an environment with certain resources (food, shelter, breeding sites, favorable temperature and suitable humidity) in sufficient amount and at appropriate time for survival and development. Mosquitoes are one of the most important vectors of disease globally. Mortality due to malaria peaked at 1.82 million in 2004 and fall as a result of more sensitive diagnostic tools, effective use of ant malarial drugs, improved personal protection and mosquito control to 1.24 million in 2010 $(714,000$ children $<5$ years and 524,000 individuals $\geq \mathrm{g} 5$ years) and over $80 \%$ of the malaria mortality occur in sub-Saharan Africa (WHO, 2006).

Currently, more than 2000 mosquito species have been identified worldwide, many of which are known vectors of human diseases. Mosquito-borne diseases pose a major threat both to human populations and to the diversity of indigenous fauna throughout the world (Spielman and D'Antonio 2001), and are of particular concern in developing nations of the world where the ecology and distribution of mosquitoes are only partially documented. Various arboviruses and protozoan parasites have been widely reported around the World causing outbreaks of dengue fever and other several fatalities (WHO, 2006). Furthermore, a number of mosquito species known to be vectors of dengue fever, West Nile virus and Ross River virus (e.g. Aedes aegypti (Linnaeus) and Ae. nocturnus (Theobold)) have been previously reported (Belkin, 1962).

Mosquito-borne diseases remain the leading health problem and it is estimated that at least 500 million people suffer from mosquitoborne diseases and more than 1.1 million people die of malaria and dengue fever annually (WHO, 2006). These diseases have accounted for huge economic loss, mortality, low productivity and social discrimination in many developing countries and to a significant health burden in developed countries via travelers who have not taken sufficient precautions and prophylactic medications before traveling. Mosquitoes are known to transmit both human and animal diseases. Among the public health and veterinary important arthropods, mosquitoes rank first in the spread of such diseases as malaria, yellow fever, filariasis, dengue fever, encephalitis as well as other viral and bacterial diseases (Gillet, 1972) and malaria is the most predominant among the mosquitotransmitted diseases.

The study investigated the environmental factors that were associated with the breeding sites in the research area, identified the breeding sites of the mosquitoes and determined the Physico-chemical parameters that influence the abundance of mosquito larvae.

\section{Methodology \\ Description of the study area}

This study was carried out in four communities (Afiesere, Ughelli main town, Ofuoma and Adjekota) in Ughelli North Local Government Area of Delta State. The area lies approximately between longitude 9'45N 8'43E of the Greenwich meridian and latitude $9.750 \mathrm{\prime} N$ 8.717 'E of the equator. It has a total area of 1440 square kilometer (Plate 1). Ughelli is one of the major urban areas in Delta state. It is a low-lying region of $0-100$ meters above sea level with hydromorphic and organic soils as the major types of soils found in the area. The soil ranges from brown to sandy loam. As a result, both types of soils tend to develop surface accumulation of peaty materials (Areola, 1987). The area is drained by river Ase, a tributary of the River Niger, and is riddled with an intricate system of natural water channels and valleys, culminating in poorly drained landscape.

Ughelli urban with a population of 82,994 was originally an agricultural settlement but has become industrialized by major oil and construction companies which include SHELL, NNPC, SETRACO. There are also other commercial organizations in the town such as banks, medical centers, educational centers, hotels, and religious organizations. The major form of public transportation is the tricycle, popularly known as Keke. In recent times, there has been great migration into the area from other 
parts of the Niger Delta and Nigeria in general, making the town a "melting pot" of all major tribes in the country as well as foreigners.

Trading is one of the major activities of the people in the area and it occurs in the various markets such as main market, Ekiugbo,
Afiesere, meat and other surrounding markets, where large numbers of traders in the towns and its environs carry out their commercial activities. Some of the marketing operations gave rise to insanitary conditions due to indiscriminate disposal of waste in these areas.

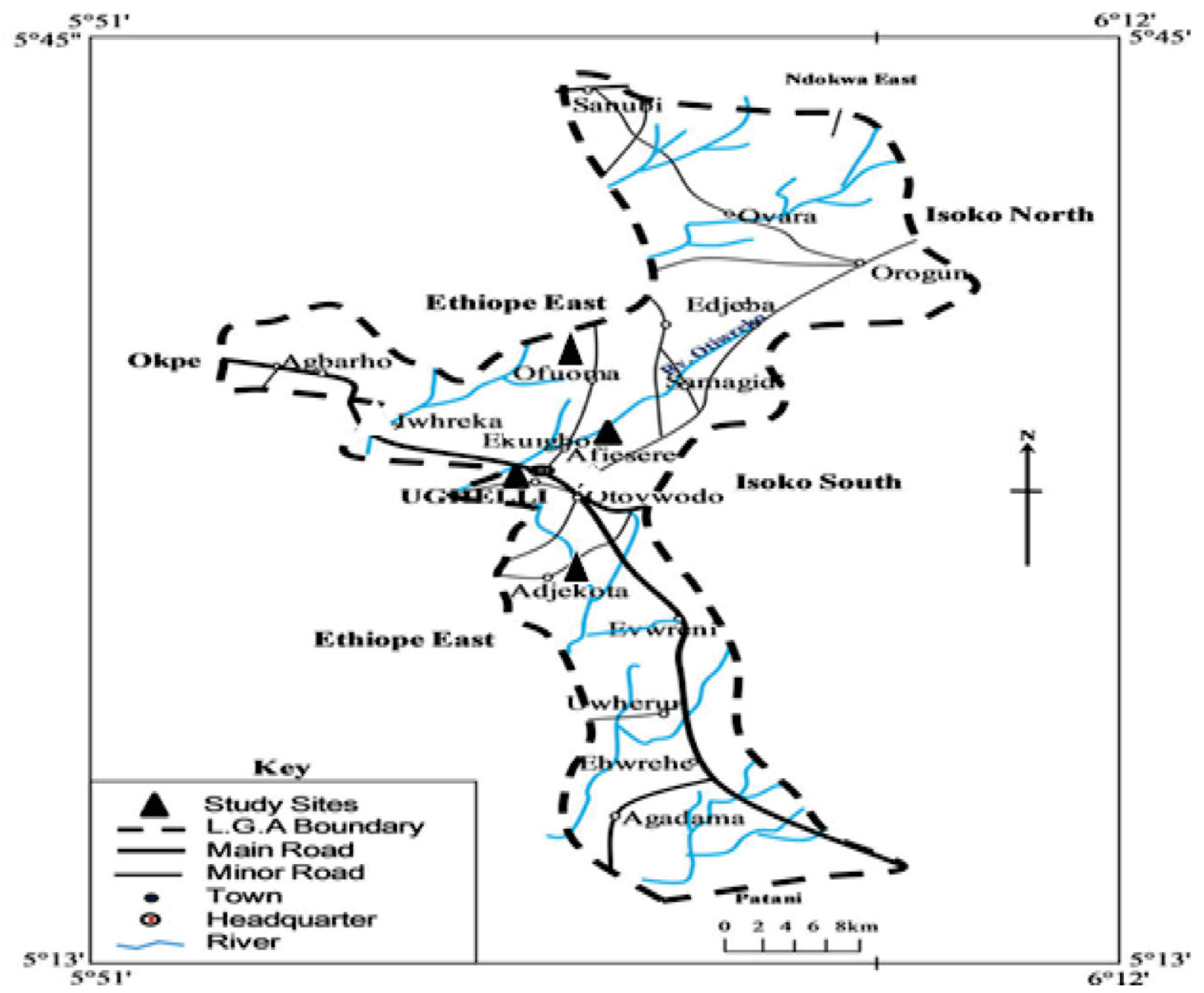

Figure1: Map of Ughelli North showing the study area extracted from google Maps (2014)

\section{Habitat Sampling}

Water bodies in different location were considered a potential breeding site of mosquitoes. Mosquito larvae were collected on weekly basis in the morning between the hours of 6:30 to 10:00am for six months (June to November 2014). Materials used for mosquito larvae sampling included locally constructed dipper, pipette, specimen bottle, hand lens. Mosquitoes breeding sites that were found in the sampling locations were grouped into the following categories, based on size (area and depth), nature of substrate (plastic, rubber, metal, concrete and soil) and habitats origin (natural or artificial). The groups were:
1. Puddles such as rain water collections on road sides, pools of water around public taps and ponds.

2. Domestic water containers like discarded pots, plastic and rubber containers, metallic containers and tin cans.

3. Discarded and commercial vehicles tyres.

4. Drains which included gutters and domestic run-offs bathrooms.

\section{Sampling Procedure}

The sampling methods used were adopted from Service (1993), depending on the 


\section{Habitat Sampling}

Water bodies in different location were considered a potential breeding site of mosquitoes. Mosquito larvae were collected on weekly basis in the morning between the hours of 6:30 to 10:00am for six months (June to November 2014). Materials used for mosquito larvae sampling included locally constructed dipper, pipette, specimen bottle, hand lens. Mosquitoes breeding sites that were found in the sampling locations were grouped into the following categories, based on size (area and depth), nature of substrate (plastic, rubber, metal, concrete and soil) and habitats origin (natural or artificial). The groups were:

1. Puddles such as rain water collections on road sides, pools of water around public taps and ponds.

2. Domestic water containers like discarded pots, plastic and rubber containers, metallic containers and tin cans

3. Discarded and commercial vehicles tyres.

4. Drains which included gutters and domestic run-offs bathrooms.

\section{Sampling Procedure}

The sampling methods used were adopted from Service (1993), depending on the types and sizes of water being sampled. The larvae in ground pools, drains and large domestic containers were collected with the aid of dippers and bowls. The dipper was a locally constructed plastic cup with long wooden handle specially designed to collect both water and mosquito larvae when dipped into a water body.

In each site, 10 dips were made in places likely to harbor mosquito larvae such as submerged vegetation or substrate edge of water bodies. For small containers like tin cans, broken or discarded house utensils were sampled by emptying the whole content of the containers into a bowl and the mosquito larvae were carefully picked with dropping pipettes and transferred into labeled specimen bottle half filled with water and taken to the laboratory.

\section{Determination of Physico-chemical parameters of water}

Physico-chemical characteristics of each habitat were recorded on a field sampling using Mafiana et al., 1998) method which includes transparency (turbidity), water temperature, conductivity, and $\mathrm{pH}$. Samples of water from each habitat were collected into $250 \mathrm{ml}$ bottles and $2.0 \mathrm{ml}$ of Winkler's solution A was added using a syringe. This was followed by the addition of $2.0 \mathrm{ml}$ Winkler's solution $B$ and taken to the laboratory for physicochemical analysis for dissolved oxygen(DO). The depths of water in the habitat were obtained by lowering a meter rule to the bottom of the water.

\section{Mosquito Rearing}

Mosquito larvae were collected from two hundred and seventy four (274) sites. The larvae collected from each sites were counted and recorded before transferring them into rearing bowls containing distilled water. Mosquito cages were netted to prevent the adults from escaping while allowing for sufficient ventilation. Mosquito larvae were fed with diet of bakers' yeast and mashed Yale Carbin biscuit for a week. Pupae emerged after 7 days and adults after 3-4 days. The adult mosquitoes that emerged were collected using mouth aspirator and subsequently identified.

\section{Identification of Mosquitoes}

Identification was carried with the aid of a light microscope using morphological characters of the keys of Gilles and Coetee (1987). The mosquitoes were identified using such morphological feature as the body color, nature of the antennae, palps and the marking on the thorax. Prior to the identification, the male mosquitoes were differentiated from females using the hairy nature of antennae, and the length of the palps.

\section{Statistical Analysis}

The data were analyzed using relative frequencies and mean values. Charts were also used to express some of the observations. The relative abundance and distribution of the mosquito genera and species were determined and expressed as percentage of the total using two way Analysis of variance (ANOVA).

Shannon-Wiener index was used to analyze the species diversity, abundance and distribution in the study area. The formula of the Shannon-Wiener index is

$$
\mathrm{H}=\quad\left(\mathrm{N} \log \mathrm{N}-\sum \text { ni } \log \mathrm{ni}\right)
$$


Where; $\mathrm{ni}=$ abundance of individual species in the ith

$\mathrm{N}=$ total number of individuals in the species (Murray and Larry 2008) $\sum\left(\mathrm{ni} / \mathrm{N}^{2}\right)$ In addition, Simpson dominance index was used to evaluate the prevalence of each individual species. The index is expressed as

$\mathrm{C}=\sum\left(\mathrm{ni} / \mathrm{N}^{2}\right)$

Where; ni is the abundance of individual species

$\mathrm{N}=$ the total number of individuals of all species (Murray and Larry 2008).

\section{RESULTS}

\section{Occurrence of mosquito larvae in the sampled sites}

Out of the 274 larval habitats sampled from the four study areas, $146(53.3 \%)$ were mosquito larvae were recorded and they occurred as follows: Afiesere 35(53.8\%), Ughelli 64(59.8\%), Ofuoma 28(43.1\%) and Adjekota 19(51.4\%). There were a total of one thousand six hundred and fifty three (1653) larvae collected from all the study sites in the four study locations in Ughelli North.

The relative abundance of mosquito larvae in the study area is $10.95 \%$ with an average of six larvae per habitat. The relative abundance of the larvae from Afiesere, Ughelli,
Ofuoma and Adjekota study sites were 11.3, $12.1,10.6$ and $9.8 \%$ respectively. Ughelli had the highest number of larvae $(12.1 \%)$ while the least abundance was recorded in Adjekota $(9.8 \%)$. However, there was no significant difference in the occurrence of mosquito larvae in the different study sites $(\mathrm{P}=0.1156)$. The mean total number of larvae per habitat is 6.0 while the mean larvae in Ughelli was (7.2), followed by Afiesere (6.1), Adjekota (5.0), and Ofouma (4.6).

A total of seven hundred and twelve (712) emerged adult mosquitoes were recorded from the entire study locations in the area sampled. Overall emergence rate of adult mosquitoes was $43.1 \%$ (712). Adult emergence was highest in Ughelli (284) and least in Adjekota (114). With regard to habitats, domestic containers accounted for the highest number of larvae collected with a total of nine hundred and ten (910). This was followed by ground puddles with a total of four hundred and twelve (412) larvae collected. Drains gave a total of two hundred and eighty three (281) larvae while discarded tyres recorded fifty (50) larvae. Also, container habitats had the highest number of emerged adults in Ughelli, followed by puddles and drains (Figure 2).

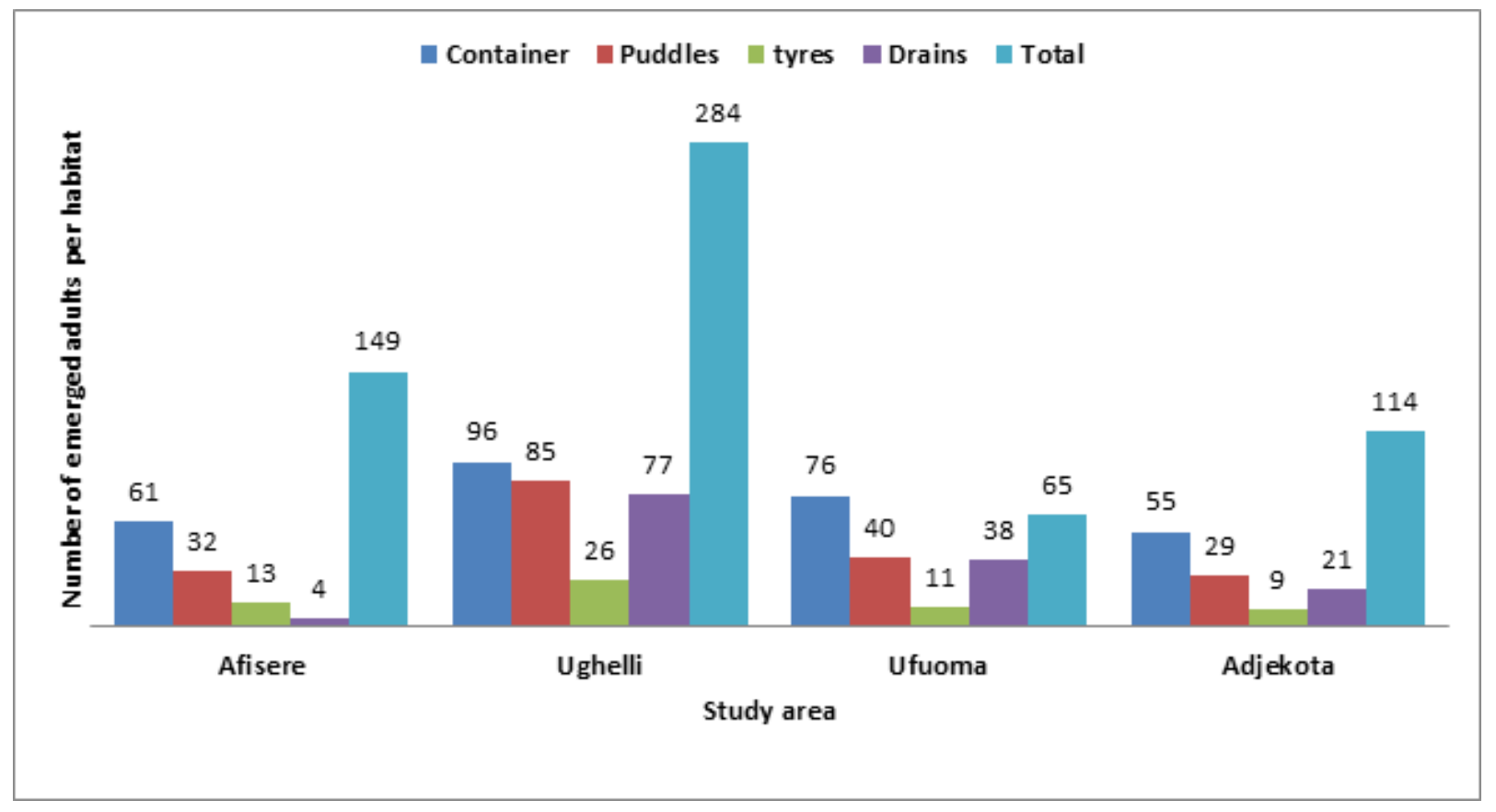

Figure 1: Number of emerged adults in different habitats 


\section{Distribution of larvae in the different locations}

Six species of mosquitoes were identified in the study area. The species are $A n$. arabansis, An. culiciafacies, Ae. aegypti, Ae. albopictus, C. quinquefasciatus and $C$. nebulosus. From the different habitats, in Afiesere, the highest species was observed to be C. quinquefasciatus with percentage occurrence of $46(30.87 \%)$ followed by Ae. aegypti 43(28.85\%), An. arabansis 21(14.09\%), Ae. albopictus, 19(12.75\%), An. culiciafacies 15(10.06\%) while C. nebulosus had the least occurrence 5(3.35\%) (Figure 2).

In Ughelli main town the highest was observed to be C. quinquefasciatus 78(27.46\%), followed by Ae. aegypti 72(25.35\%), Ae. albopictus 51(17.95\%), An. arabansis 47(16.54\%), and An. culiciafacies 27(9.50\%) while the least was $C$. nebulosus $9(3.16 \%)$. The highest species in Ofuoma was $C$. quinquefasciatus 51(30.90\%) followed by Ae. aegypti 40(24.24\%), An. arabansis 30(18.18\%), Ae. albopictus 24(14.54\%), An. culiciafacies $13(7.87 \%)$ while the least was $C$. nebulosus 7(4.24\%). Adjekota recorded the most species abundance of $C$. quinquefasciatus $34(29.82 \%)$ followed by Ae. aegypti 28(24.56\%), An. arabansis 24(21.05\%), Ae. albopictus 21(18.42\%) while the least recorded was An. culiciafacies 7(6.14\%) (Figure 2).

With regard to the study sites, Ae.aegypti and C.quinquefasciatus were the predominant species found in the study sites while C.nebulosus recorded the least occurrence. In Afiesere, Ughelli and Ofuoma Ae.aegypti and C.quinquefasciatus were found more in containers than in drains. The variation in the species of mosquito with respect to habitat types showed significant association in Ofuoma $(\mathrm{P}=0.0167, \mathrm{~F}=4.322, \mathrm{df}=3)$ and $\operatorname{Ajekota}(\mathrm{P}=$ $0.0252, \mathrm{~F}=3.852, \mathrm{df}=3$ )

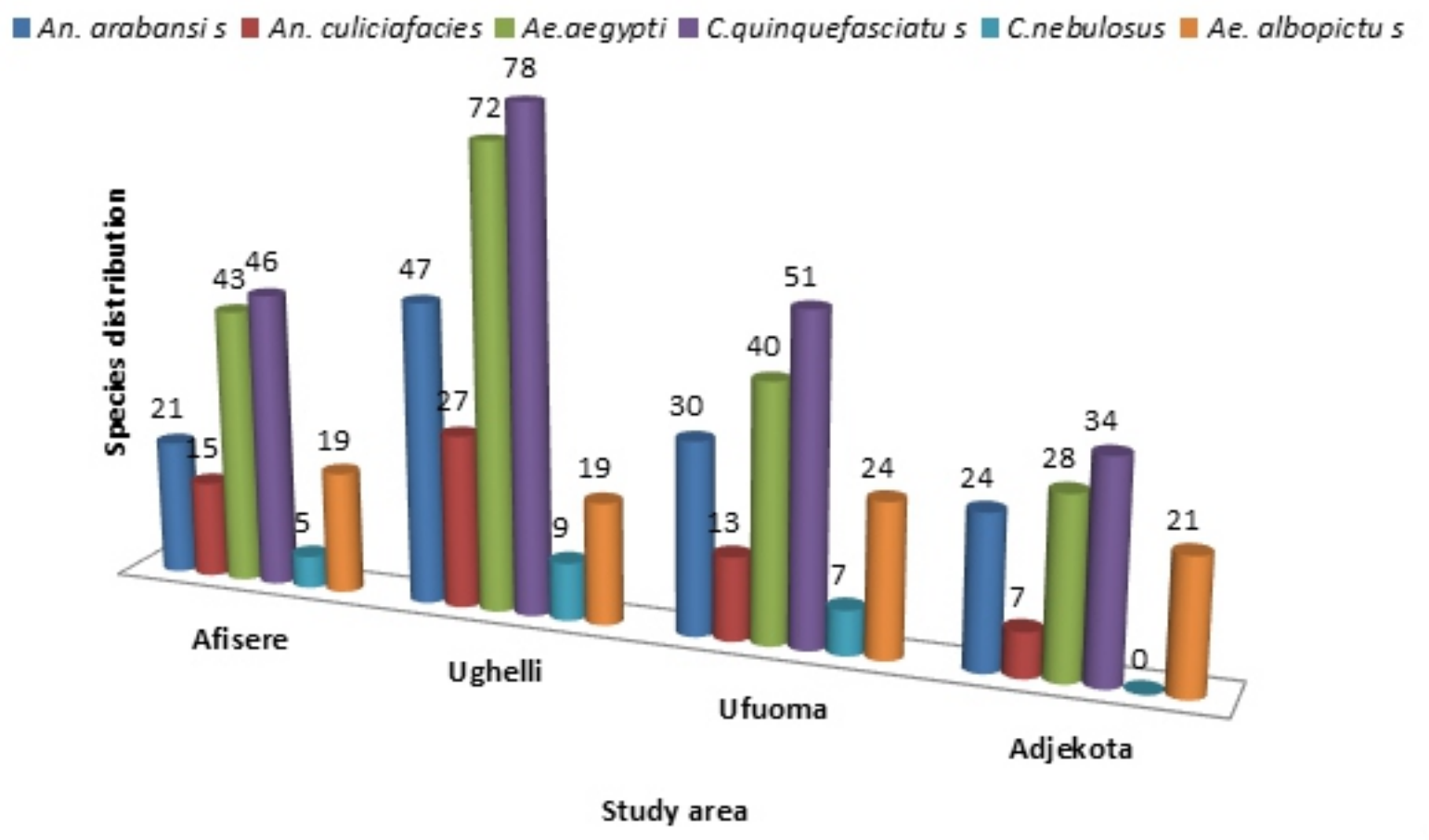

Figure 2: Mosquito species distribution in different location

\section{Temporal distribution of mosquito species in different habitats}

There was highest larval density in Ughelli main town in the month of June (205), and the least was in November (87) and in Afiesere, the highest was recorded in September (101) while the least was June (38) but in Ofuoma the highest was in recorded in June (80) and the least in October (18) as the highest was recorded in Adjekota in September (48) while the least was recorded in October (18).

There was variation in the monthly distribution of adult mosquito species in the different habitats, In puddles, there was it was highest July (46) and lowest in August/November (21) but in domestic container habitat, it was highest in July (59) and least in November (36) while discarded tyres 
was highest in July (19) and lowest in November (3) as the drain/gutter habitats has the highest distribution of adult mosquito species July (49) and least in November (8).The chronological order in the monthly occurrence of mosquito is: June (122), July (173), August (105), September
(136), October (108) and November (68). Thus the frequency of mosquito occurrence was highest in July and least in November while the occurrence of mosquito larvae in drains decreases with increase in months (Table 1).

Table 1: Temporal distribution of mosquito species in different habitats in the study area

\begin{tabular}{|c|c|c|c|c|c|c|c|}
\hline & & Containers & Puddles & Tyres & Drains & Total & $P$ value $(\mathrm{F})$ \\
\hline \multirow[t]{7}{*}{ June } & An.arabansis & 12 & 6 & 3 & 3 & 24 & \\
\hline & An. Culiciafacies & 2 & 4 & 0 & 7 & 13 & 0.0518 \\
\hline & Ae.aegypti & 9 & 10 & 3 & 10 & 32 & $(3.031)$ \\
\hline & Ae.albopictus & 12 & 3 & 1 & 5 & 21 & \\
\hline & C.quinquefasciatus & 10 & 5 & 4 & 8 & 27 & \\
\hline & C.nebulosus & 0 & 0 & 0 & 5 & 5 & \\
\hline & Total & 45 & 28 & 11 & 38 & 122 & \\
\hline \multirow[t]{35}{*}{ July } & An.arabansis & 8 & 8 & 2 & 6 & 24 & \\
\hline & An.culiciafacies & 3 & 2 & 2 & 4 & 11 & 0.2370 \\
\hline & Ae.aegypti & 11 & 15 & 3 & 13 & 42 & $(1.532)$ \\
\hline & Ae.albopictus & 10 & 9 & 2 & 10 & 31 & \\
\hline & C.quinquefasciatus & 25 & 12 & 8 & 13 & 58 & \\
\hline & C.nebulosus & 2 & 0 & 2 & 3 & 7 & \\
\hline & Total & 59 & 46 & 19 & 49 & 173 & \\
\hline & An.arabansis & 5 & 4 & 4 & 3 & 16 & \\
\hline & An.culiciafacies & 3 & 0 & 0 & 5 & 8 & 0.1920 \\
\hline & Ae.aegypti & 11 & 8 & 5 & 6 & 30 & $(1.735)$ \\
\hline & Ae.albopictus & 3 & 6 & 0 & 8 & 17 & \\
\hline & C.quinquefasciatus & 20 & 3 & 1 & 6 & 30 & \\
\hline & C.nebulosus & 1 & 0 & 1 & 2 & 4 & \\
\hline & Total & 43 & 21 & 11 & 30 & 105 & \\
\hline & An.arabansis & 9 & 10 & 3 & 8 & 30 & \\
\hline & An.culiciafacies & 8 & 4 & 0 & 3 & 15 & 0.0085 \\
\hline & Ae.aegypti & 14 & 12 & 0 & 8 & 34 & $(5.132)$ \\
\hline & Ae.albopictus & 16 & 5 & 0 & 7 & 28 & \\
\hline & C. quinquefasciatus & 8 & 9 & 4 & 5 & 26 & \\
\hline & C.nebulosus & 2 & 0 & 0 & 1 & 3 & \\
\hline & Total & 57 & 40 & 7 & 32 & 136 & \\
\hline & An.arabansis & 7 & 7 & 2 & 2 & 18 & \\
\hline & An.culiciafacies & 4 & 3 & 0 & 1 & 8 & 0.0534 \\
\hline & Ae.aegypti & 10 & 6 & 1 & 8 & 25 & $(3.029)$ \\
\hline & Ae.albopictus & 8 & 4 & 0 & 2 & 14 & \\
\hline & C.quinquefasciatus & 18 & 10 & 5 & 8 & 41 & \\
\hline & C.nebulosus & 1 & 0 & 0 & 1 & 2 & \\
\hline & Total & 48 & 30 & 8 & 22 & 108 & \\
\hline & An.arabansis & 5 & 3 & 0 & 1 & 9 & \\
\hline & An.culiciafacies & 5 & 2 & 0 & 0 & 7 & 0.0241 \\
\hline & Ae.aegypti & 9 & 8 & 1 & 3 & 21 & $(3.900)$ \\
\hline & Ae.albopictus & 4 & 0 & 0 & 0 & 4 & \\
\hline & C.quinquefasciatus & 13 & 8 & 2 & 4 & 27 & \\
\hline & C.nebulosus & 0 & 0 & 0 & 0 & $\mathbf{0}$ & \\
\hline & Total & 36 & 21 & 3 & 8 & 68 & \\
\hline
\end{tabular}




\section{Physico-chemical parameters of larval habitats in the study locations}

There were variations in the mean range of physico-chemical parameters in the different sources of collections in different locations. Temperature ranged from 20.0 to $24.6^{\circ} \mathrm{C}$ in the various locations with the highest in the gutter sites at Ughelli main town. The $\mathrm{pH}$ (hydrogen ion concentration) varied from acidic to alkaline in the study area at different locations. The range of $\mathrm{pH}$ was $6.9-7.7$ with the highest obtained at Ofuoma and the least at Ughelli in containers. Dissolved oxygen (D.O) ranged between 1.4 and $2.7(\mathrm{mg} / \mathrm{L})$ in the different locations with the highest obtained at Ofuoma in the gutter collection sites (Table 2).

Conductivity ranged between 67.9 and $82.1(\mu \mathrm{s})$ with highest in gutter collection sites at Ughelli main town and lowest from containers at
Afiesere. The result of turbidity varied from 62.0NTU in the container samples to $84.2 \mathrm{NTU}$ in the gutter samples at Afiesere with the lowest and Adjekota. Afiesere had the highest turbidity values. The depth varied between 6.3 and $68.3(\mathrm{~cm})$ across the different locations and sources of collection in the study area. The lowest depth of $6.3 \mathrm{~cm}$ was recorded in containers at Afiesere while the highest depth $(68.3 \mathrm{~cm})$ was recorded in Adjekota study location in gutter sampling sites. In Afiesere, the mean temperature was highest in container habitat (22.8 \pm 2.6$)$, while $\mathrm{pH}$ was highest in puddles (22.2 \pm 1.2$)$. Also, conductivity and turbidity were highest in drain habitat types (Table 2). Depth was consistently highest in drains and least among container habitat types. The dissolved oxygen values were relatively similar for all habitat types (Table 2).

Table 2: Physico-chemical parameters of larval habitats in the study locations

\begin{tabular}{|c|c|c|c|c|c|}
\hline \multirow[t]{2}{*}{ Sites } & \multirow{2}{*}{$\begin{array}{l}\text { Parameters } \\
(\text { mean } \pm \text { SE })\end{array}$} & \multicolumn{4}{|c|}{ Habitat types } \\
\hline & & Containers & Puddles & Tyres & Drains \\
\hline \multirow[t]{6}{*}{ Afiesere } & Temp. $\left({ }^{\circ} \mathrm{C}\right)$ & $20.9-24.6(22.8 \pm 2.6)$ & $21.3-23.1(22.2 \pm 1.2)$ & $20.6-24.1(22.4 \pm 2.4)$ & $20.8-25.1(23.0 \pm 3.0)$ \\
\hline & $\mathrm{pH}$ & 7.1-7.4(7.3 \pm 0.2$)$ & 7.3-7.7(7.5 \pm 0.3$)$ & $7.0-7.5(7.3 \pm 0.4)$ & 7.2-7.3(7.3 \pm 0.1$)$ \\
\hline & D.O. (mg/L) & $1.4-1.9(1.7 \pm 0.4)$ & $1.9-2.2(2.1 \pm 0.2)$ & $2.7-2.8(2.8 \pm 0.1)$ & $1.6-1.9(1.8 \pm 0.2)$ \\
\hline & Conduct. $(\mu \mathrm{s})$ & $66.4-69.4(67.9 \pm 2.1)$ & $73.1-78.2(75.7 \pm 3.6)$ & $80.2-82.9(81.6 \pm 1.9)$ & $72.3-76-5(74.4 \pm 0.9)$ \\
\hline & Turbidity (NTU) & $60.8-63.1(62.0 \pm 1.6)$ & $74.3-79.2(76.6 \pm 3.6)$ & $79.2-81.3(80.3 \pm 1.5)$ & $81.7-86.7(84.2 \pm 3.5)$ \\
\hline & Depth $(\mathrm{cm})$ & $5.6-7.0(6.3 \pm 0.9)$ & $14.3-17.4(15.9 \pm 2.2)$ & $8.6-11.1(9.9 \pm 1.7)$ & $52.7-68.3(60.5 \pm 11.0)$ \\
\hline \multirow[t]{6}{*}{ Ughelli } & Temp. $\left({ }^{0} \mathrm{C}\right)$ & $20.6-22.8(21.7 \pm 1.6)$ & $22.5-26.3(24.4 \pm 2.7)$ & $20.1-27.1(23.3 \pm 4.9)$ & $23.7-25.1(24.6 \pm 0.9)$ \\
\hline & $\mathrm{pH}$ & $6.7-7.1(6.9 \pm 0.3)$ & $7.1-7.6(7.2 \pm 0.3)$ & $7.0-7.7(7.3 \pm 0.5)$ & $6.9-7.2(7.0 \pm 0.2)$ \\
\hline & D.O. (mg/L) & $2.1-2.6(2.3 \pm 0.3)$ & $2.0-2.5(2.1 \pm 0.4)$ & $1.6-2.1(1.9 \pm 0.4)$ & $2.1-2.3(2.3 \pm 0.1)$ \\
\hline & Conduct. $(\mu \mathrm{s})$ & $72.8-77.1(74.2 \pm 3.0)$ & $77.4-81.0(76.1 \pm 2.5)$ & $78.0-83.5(81.2 \pm 3.9)$ & $79.1-85.7(82.1 \pm 4.6)$ \\
\hline & Turbidity (NTU) & $77.1-82.3(78.9 \pm 3.7)$ & $74.6-80.2(77.3 \pm 3.9)$ & $81.3-82.6(81.3 \pm 0.9)$ & $80.5-84.2(81.6 \pm 2.6)$ \\
\hline & Depth $(\mathrm{cm})$ & 7.5-8.9(7.9 \pm 0.9$)$ & $12.3-16.4(14.6 \pm 2.8)$ & $9.5-11.3(11.0 \pm 1.3)$ & $\begin{array}{l}48.4-61.4(50-6 \pm 9.1) \\
237-261(24-2 \pm 16)\end{array}$ \\
\hline \multirow[t]{5}{*}{ Ofuoma } & $\begin{array}{l}\text { Temp. }\left({ }^{0} \mathrm{C}\right) \\
\mathrm{pH}\end{array}$ & $\begin{array}{l}19.1-20.6(20.0 \pm 1.1) \\
7.7-7.8(7.7 \pm 0.1)\end{array}$ & $\begin{array}{l}22.1-25.3(23.7 \pm 2.3) \\
7.4-7.7(7.6 \pm 0.2)\end{array}$ & $\begin{array}{l}21.8-24.2(22.2 \pm 1.7) \\
7.3-7.7(7.4 \pm 0.3)\end{array}$ & $\begin{array}{l}23.7-26.1(24.2 \pm 1.6) \\
7.0-7.5(7.2 \pm 0.4)\end{array}$ \\
\hline & D.O. (mg/L) & $1.9-2.2(2.0 \pm 0.2)$ & $2.1-2.5(2.3 \pm 0.3)$ & $2.3-2.7(2.6 \pm 0.2)$ & $2.7-2.9(2.7 \pm 0.1)$ \\
\hline & Conduct. $(\mu \mathrm{s})$ & $81.3-86.4(83.2 \pm 3.6)$ & $88.1-96.4(90.1 \pm 5.8)$ & $86.4-88.7(87.1 \pm 1.6)$ & $77.6-81.0(78.9 \pm 2.4)$ \\
\hline & Turbidity (NTU) & $66.7-70.3(68.4 \pm 2.5)$ & $73.4-78.1(76.2 \pm 3.3)$ & $73.2-75.9(74.1 \pm 1.9)$ & $82.4-87.3(84.2 \pm 3.4)$ \\
\hline & Depth $(\mathrm{cm})$ & $5.6-8.4(6.8 \pm 1.9)$ & $15.6-19-7(18.1 \pm 2.5)$ & $7.3-11.7(9.3 \pm 3.1)$ & $61.0-72.8(66.3 \pm 8.3)$ \\
\hline \multirow[t]{6}{*}{ Adjekota } & Temp. $\left({ }^{0} \mathrm{C}\right)$ & $20.2-25-8(24.1 \pm 2.3)$ & $24.1-27.3(25.3 \pm 2.2)$ & $22.0-25.1(24.0 \pm 2.1)$ & $21.5-26.7(23.8 \pm 3.6)$ \\
\hline & $\mathrm{pH}$ & 7.2-7.7(7.6 \pm 0.4$)$ & 7.0-7.6(7.3 \pm 0.4$)$ & $7.5-7.9(7.7 \pm 0.3)$ & 7.4-7.5(7.5 \pm 0.1$)$ \\
\hline & D.O. (mg/L) & $1.9-2.3(2.1 \pm 0.3)$ & $2.2-2.5(2.3 \pm 0.2)$ & $2.3-2.6(2.5 \pm 0.2)$ & $1.8-2.1(2.0 \pm 0.2)$ \\
\hline & Conduct. $(\mu s)$ & $71.6-75.3(73.1 \pm 2.6)$ & $75.2-77.4(75.9 \pm 1.5)$ & $81.0-85.3(83.2 \pm 3.0)$ & $79.6-84.3(81.6 \pm 3.3)$ \\
\hline & Turbidity (NTU) & $60.2-66.1(63.4 \pm 4.2)$ & $73.9-77.8(74.2 \pm 2.7)$ & $78.6-81.1(80.2 \pm 1.7)$ & $82.1-84.6(83.9 \pm 1.7)$ \\
\hline & Depth $(\mathrm{cm})$ & $5.9-7.3(6.4 \pm 0.9)$ & $12.8-16.4(14.8 \pm 2.5)$ & $6.2-8.7(7.4 \pm 1.7)$ & $52.6-77.1(68.3 \pm 17.3)$ \\
\hline
\end{tabular}

\section{Discussion}

In this study, there was relatively high abundance of mosquito larvae in the study locations. The result showed high larvae abundance of 1653 . There were variations in the results obtained in the different locations with percentage of occurrence as follows: Afiesere (53.8\%), Ughelli (59.8\%), Ofuoma (43.1\%) and Adjekota (51.4\%). The result obtained from this study showed that the distribution and 
abundance of mosquito species was significantly different $(\mathrm{p}<0.05)$ across the four locations in Ughelli North Local Government Area of Delta State. The percentage relative abundance of mosquito larvae was $11.3 \%$ with an average of six larvae per habitat. Ughelli main town recorded the highest abundance $(12.1 \%)$. This was followed by Afiesere $(11.3 \%)$ and Ofuoma $(10.6 \%)$ while the least was recorded at Adjekota (9.8\%) in the various larval habitats including containers, puddles, tyres and drains. This showed that there was high number of breeding sites observed in the study area. This high number of breeding sites could be attributed to the different human activities, poor economic conditions, and abundant numbers of construction sites, poor sanitation level and indiscriminate disposal of discarded household materials.

In the present study six species were collected from the three genera of mosquitoes. Based on the species encountered, the study revealed that $A e$. a egypti and $C$. quinquefasciatus are the predominant species found in the study sites while C. nebulosus recorded the least occurrence. In the different locations studied, such as Afiesere, Ughelli and Ofuoma, Ae. aegypti and C. quinquefasciatus were observed more in containers than in drains. The variation in the species of mosquito with respect to habitat types showed significant association in Ofouma and Ajekota. All species of mosquitoes reported in this study have also been reported by different researchers elsewhere in Nigeria.

This indiscriminate breeding habit has long been reported by Okorie (1987), Mafiana et al. (1998) and Adeleke (2003). Both Ae. aegypti and Ae. albopictus have been implicated in the transmission of yellow fever and other arboviruses. Though, yellow fever epidemics have not been reported recently in the study area, the outbreak of the disease had been reported in different States (Mbanugo and Opkalaonuju, 2003).

The occurrence of $C x$. quinquefasciatus in containers in the present study is common because of its preference for polluted water. This agrees with the findings of Services, (1993) who stated that C.quinquefasciatus was the dominant species in polluted habitats in urban areas and $C$. nebulosus has become rare except in rural areas. Culex spp disease vector encountered in the study include $C x$. Quinquefasciatus which is known vector of Bancroftian filariasis as well as a potential vector of arboviruses in general. The Anopheles spp encountered in the study is a potential vector of malaria. The relative abundance of Anopheles spp in both natural and artificial breeding sources indicates a higher potential for malaria transmission (Okogun et al., 2003).

In conclusion, this study has established that although both species of mosquitoes may exploit the same habitat for larval development, they respond differently to habitat factors resulting in niche partitioning. These results have shown that poor sanitation which include improper disposal of solid waste and sewage contributes significantly to larval development of mosquitoes. Therefore, our environment should be kept clean by removing all possible breeding sites of mosquitoes such as domestic containers, tyres, puddles and drains

\section{References}

Adeleke, M.A. (2003). Mosquito species breeding in artificial containers in Ikenne farm settlement, Ogun State, Nigeria. BSc Dissertation, University of Agriculture, Abeokuta 35pp.

Aigbodion, F.I. and Anyiwe, M.A. (2005). Mosquitoes and the environments: some economic costs of malaria in Nigeria. Nigerian Journal of Entomology, 22, 93107.

Belkin, J. N. (1962). The mosquitoes of the South Pacific (Diptera, Culicidae). Berkeley, University of California Press, Vol. 1, 608 pp.; Vol. 11, plates 1412.

Gillet, J.D. (1972). Common African Mosquitoes and their Medical Importance. William Heinemann Medical Books LTD, UK. 236pp.

Gillies, M.T. and Coetzee, B.A. (1987). Supplementary to Anophelinae of Africa, South of Sahara (Afro-Tropical Region). Publication of the South African Institute of Medical Research 55:1-143.

Mafiana, C.F., Anaeme, L. and Olatunde, G.O. (1998). Breeding sites of larval mosquitoes in Abeokuta, Nigeria. Nigerian Journal of Entomology, 15:136-143. 
Mbanugo, J.I. and Okpalaononuju, C.N. (2003).Surveillance of Mosquito Vectors in some Habitats of Awka Metropolis, Anambra, Nigeria. Nigerian Journal of Parasitology 24:184-190.

Murray, R.S. and Larry, J.S. (2008) Schaum;s Outlines of Theory and Problems of Statistics.ISBN 978-0 07-148584-5.

Okogun, G.R.A., Nwoke, B.E.B., Okere, J.C. and Anegbe, C. (2003).Epidemiological Implications of Preferences of Breeding Sites of Mosquito Species in Midwestern Nigeria. Annals of Agriculture and Environmental Medicine 10: 217-222.

Okorie, T.G. (1987). The breeding site preferences of mosquito species in Ibadan, Nigeria. Nig J Ent, 1(3): 71-80.

Service, M.W. (1993). Mosquitoes (Culicidae). In: Lane RP, Crosskey RW (Eds) Medical Insects and Arachnids. Chapman and Hall. London, pp. 120240.

Spielman, A. and D'Antonio, M. (2001). Mosquito: A Natural History of Our Most Persistent and Deadly Foe. Faber and Faber, London, UK.

World Health Organization (WHO). 2006. Health Situation. [Cited 13 Sep 2007.] A v a i 1 a b 1 e from U R L : http://www.wpro.who.int/countries/ton/hea 1th situation.htm. accessed March, 2014. 